\title{
Quorum quenching intervened in vivo attenuation and immunological clearance enhancement by Solanum torvum root extract against Pseudomonas aeruginosa instigated pneumonia in Sprague Dawley rats
}

Kayeen Vadakkan ${ }^{1}$, Janarthanam Hemapriya ${ }^{2}$ and Vijayanand Selvaraj ${ }^{\text {* }^{*}}$

\begin{abstract}
Background: Pseudomonas aeruginosa have been delineated for its disreputable charisma in nosocomial infections leading to pulmonary pneumonia. The recent developments in multi-drug resistance accelerate the need of alternative antibacterial strategies. In this study we analysed the efficacy of quorum quenching mediated bacterial silencing in effective immunological clearance upon pulmonary infected rat models.

Results: Quorum sensing inhibitor was extracted from Solanum torvum which is a native plant in Kerala, India. The in vitro pilot studies upon Pseudomonas aeruginosa strain jb07 revealed the ability of Solanum torvum root extract (STRE) to successfully inhibit quorum sensing controlled virulent factors such as chromogenesis and biofilm formation; though the bacterial growth was unaffected. In vivo analysis upon Sprague Dawley rats shown the potential of STRE in aiding successful bacterial clearance where in cent percentage of survival was evident that compared with untreated group. Subjects treated with STRE possessed natural immunological response with inflammation, MNC infiltration and BALT (bronchus associated lymphoid tissue) hyperplasia unlike the Ciprofloxacin treated comparative group.

Conclusions: The observations of this study suggests that STRE is not having any bactericidal activity rather its silencing the infectant in a system which in turn disables the virulence of bacteria and remain attenuated; therefore immune system get adequate time for successful countermeasures.
\end{abstract}

Keywords: Pseudomonas aeruginosa, Pulmonary infection, Solanum torvum, Quorum sensing, Quorum quenching

\section{Background}

Bacteria interact with each other using chemical signalling molecules called autoinducers by a density dependent mechanism termed as quorum sensing. This enables the synchronization of large bacterial group activities such as pigment production, biofilm formation, swarming motility, toxin production and exozyme secretion [1]. Depending upon the type of autoinducers, quorum sensing can be

\footnotetext{
* Correspondence: selvarajvijayanand76@gmail.com

'Bioresource Technology lab, Department of Biotechnology, Thiruvalluvar University, Vellore, TN 632115, India

Full list of author information is available at the end of the article
}

categorized into three. Acyl homoserine lactone (AHL) mediated quorum sensing which is exhibited exclusively by gram negative bacteria, peptide mediated signalling which is observed in gram positive bacteria and LuxS controlled autoinducer-2 intervened communication, which is seen in both gram negative and gram positive bacteria [2]. To be precise quorum sensing is the summation of synthesis, release, identification and responding to autoinducers. Bacteria exploit the highly specific nature of signalling molecules when they are in an endosymbiotic locale, due to which communication among one species will be intact from signalling molecules of other spices, hence no cross 
talking between species [3]. Such extreme specificity is achieved by peculiar signal- receptor binding sites that recognize only specific signal [4]. In gram negative bacteria a vast diversity of LuxI/LuxR homologues genes are studied for its quorum sensing regulation, such as LuxI/LuxR in Vibrio harveyi regulating the bioluminance [5]; SmaI/ SmaR controlled production of carbapenem, prodigiosin, pectate lyase and cellulase in Serratia marcescens [6]; LasI/ LasR and Rhil/RhiR mediated virulence factors synthesis by Pseudomonas aeruginosa [7]. The studies on quorum sensing architecture suggest that it is possible to inhibit quorum sensing mediated bacterial virulence by suppressing bacterial communication.

Quorum sensing can be inhibited by various methods which is collectively called as quorum quenching wherein, the signalling mechanism is repressed without effecting the bacterial growth. Due to this the virulent properties of pathogens are suppressed, as a result host defence mechanism gets adequate exposure and time for effective bacterial clearance [8]. Quorum quenching protocols can be broadly classified into two groups such as enzymatic inhibition and non-enzymatic inhibition. Enzymatic inhibition includes the degradation of signalling molecule by the usage of enzymes like lactonase, acylase, oxidoreductase etc,,which will consecutively disable the signalling pathway [9]. Non-enzymatic bacterial silencing can be attained by approaches like signal synthesis inhibition, competitive or allosteric inhibition of signal binding to response gene and through blocking signal reception by response gene through modification and conformational changes of signalling molecule structure [10].

Despite numerous beneficial characteristics of bacteria, the infections caused by them are crafting new life threatening medical conditions. There have been several approaches used for the annihilation of bacterial pathogens, out of which antibiotic mediated inhibition was found to be most efficacious. The principle behind antibiotics are to inhibit essential mechanisms of bacterial existence such as cell wall synthesis, DNA replication and protein synthesis [11]. This is a direct bacterial destruction mechanism where drugs target pathogens directly in which the host immune system does not have much impact on bacterial neutralization. At present the antibacterial efficiency of antibiotic drugs are under peril due to the surge of multi drug resistant strains. Various antibiotic resistant strains such as Escherichia coli O104, Klebsiella pneumoniae NDM-1 were identified since the report of first antibiotic resistant Staphylococcus aureus in mid-nineteenth century. It is assumed that over $70 \%$ of total pathogens are resistant towards at least one of the commercially available antibiotics [12]. To gear up the conditions vilest, discovery of new antibiotics has become limited resulting in a compulsion to implement alternative therapeutic methods to suppress multidrug resistant bacterial outbreak. In this circumstance, quorum quenching dependent bacterial attenuation can be exploited to target bacterial virulence and successive bacterial clearance.

Several natural and synthetic products have been proclaimed for their positive quorum quenching capability, though not many of them has been adopted to therapeutic level either due to lack of extensive study or because of toxicity [13]. Accordingly it's important to exploit novel sources for biocompatible quorum quenching agents that could maintain its property in vivo. In this study we are analysing the influence of Solanum torvum root extract upon quorum sensing regulated virulent properties of Pseudomonas aeruginosa and evaluated its potential therapeutic property upon in vivo lung infection model for efficacious bacterial clearance.

\section{Methods}

Sample collection and extract preparation

Solanum torvum was collected from Thrissur District, Kerala, India (Latitude: 10.5890536 and Longitude: 76.0971808). The identity of sample was authenticated by rbcL gene sequencing and nucleotide blast, later submitted in NCBI under the accession number KU599936. Root of collected plant was washed and chopped into small pieces. Sample was then dried in sunlight for 6 days until all moisture content was removed. Subsequently dried sample was made into fine power and boiled in water for $3 \mathrm{~h}$ at $100^{\circ} \mathrm{C}$. The resulting suspension was filtered which was further concentrated and dried under controlled laboratory conditions to obtain STRE(Solanum torvum root extract) [14]. However the bioactive compound responsible for quorum quenching activity was found to be 2-Hydroxyanisole by GC-MS analysis in our pilot studies.

\section{Bacterial strain and maintenance}

Clinical isolate Pseudomonas aeruginosa strain jp07 was used as test strain in this study. Strain was isolated from sputum and identified by $16 \mathrm{~s}$ rRNA sequencing. $\mathrm{Nu}-$ cleotide sequence of strain is been submitted in NCBI (National Centre of Biotechnological Information) under the accession number MF426269. Strain was maintained in Luria-Bertani (LB) agar slants in $4{ }^{\circ} \mathrm{C}$ with proper subculture in Bioresource Technology Lab, Department of Biotechnology, Thiruvalluvar University.

\section{Effect of STRE upon growth and in vitro bacterial attenuation}

Pigment production and biofilm formation was taken as parameters to analyse in vitro attenuation. Pyoverdin production was estimated colorimetrically by the method adopted from [15]. Pseudomonas aeruginosa Strain jb07 was grown in Luria-Bertani broth overnight at $37^{\circ} \mathrm{C}$ with varying concentrations of STRE $(0-3.0 \mathrm{mg} / \mathrm{ml})$, supernatant 
was diluted into 1:10 concentration with Tris-HCL (7.4 pH) and absorbance was taken in $405 \mathrm{~nm}$. Constant $\mathrm{pH}$ was maintained throughout the experiment to eliminate the probability of false-positive results. Effect of STRE upon biofilm formation of strain was determined by slightly modifying the method described by [16]. Briefly, $200 \mu \mathrm{L}$ aliquot of sterile LB broth and a $100 \mu \mathrm{L}$ aliquot of overnight culture of $P$. aeruginosa isolate were transferred into the 96-well microtiter plates. STRE in varying concentration $(0-3.0 \mathrm{mg} / \mathrm{ml})$ was added to it subsequently. The mixture was then incubated for $24 \mathrm{~h}$ at $37^{\circ} \mathrm{C}$. After incubation wells were washed with saline to remove weakly adhered cells. The adherent biofilms were stained with a $200 \mu \mathrm{L}$ aliquot of $0.4 \%$ crystal violet solution for ten minutes and followed by adding a standard solution of $95 \%$ ethanol. Absorbance of ethanol extract was measured at $570 \mathrm{~nm}$. Bacterial growth was determined colorimetrically at $600 \mathrm{~nm}$.

\section{Experimental animals and maintenance}

The study has been conducted in accordance with the recommendation of the Committee for the Purpose of Control and Supervision of Experiments on Animals (CPCSEA) guidelines for laboratory animal facility and approval by Institutional Animal Ethics Committee (IAEC) protocol with approval number LBPL-IAEC-16208/16, dated 14-Aug-16. The test animals (male Sprague Dawley rat, body weight ranging within 131.56-172.69 g, 7 to 8 weeks aged) were housed under standard laboratory conditions, air-conditioned with adequate fresh air supply (Air changes $12-15$ per hour), room temperature $22 \pm 30^{\circ} \mathrm{C}$, relative humidity $30-70 \%$, with $12 \mathrm{~h}$ light and $12 \mathrm{~h}$ dark cycle. Maximum of 3 animals were housed in individual cages with stainless steel mesh top grill having facilities for holding pellet food and drinking water. The animals were acclimatized for a period of 3 days to laboratory conditions and observed for clinical signs daily. The animals were fed ad libitum with standard laboratory animal feed and reverse osmosis purified drinking water was provided ad libitum. Body weight, clinical signs, and mortalities were observed and measured regularly; General observations such as food intake, salivation, muscular weakness, and reflexes were analyzed [17].

\section{Preparation of Pseudomonas aeruginosa challenge inoculation}

The preparation of bacterial challenge inoculation was carried out by modifying the methods previously described by [18]. Concisely, P. aeruginosa strain was cultured in $50 \mathrm{~mL}$ of Luria-Bertani broth for $24 \mathrm{~h}$ at $37^{\circ} \mathrm{C}$. bacterial cells were collected by centrifugation (10,000 rpm $30 \mathrm{~min})$ and resuspended in fresh broth. $1 \mathrm{~mL}$ of bacterial inoculum was mixed with nine $\mathrm{mL}$ of sterile alginate $(10 \mathrm{mg} / \mathrm{ml}$ concentration). This mixture was stored in $4{ }^{\circ} \mathrm{C}$. The animals were anesthetized by intra peritoneal injection of ketamine $(80 \mathrm{mg} / \mathrm{kg}$ body weight) and xylazine $(5 \mathrm{mg} / \mathrm{kg}$ body weight). After the animals were anesthetized, the trachea was exposed using midline incision and intubated using 26 gauge needle for bacterial inoculation. The awakened animals were put back into their home cages.

\section{Experimental Design of Animal Model}

Rats were randomly divided into four groups each containing six subjects; Group 1 was considered as negative control which was daily administrated with normal saline $(5 \mathrm{~mL} / \mathrm{Kg}$, orally) and sterile distilled water $(1 \mathrm{~mL} / \mathrm{Kg}$, orally). Other than negative control all groups was challenged with bacterial inoculation $\left(1 \times 10^{7} \mathrm{CFU} / \mathrm{rat}\right)$ on day one and day two. Group 2 was categorized as positive control infected with $5 \mathrm{~mL} / \mathrm{Kg}$ bacterial inoculum twice a day on day one and two intratracheally and sterile distilled water $(1 \mathrm{~mL} / \mathrm{Kg}$, orally) daily for 14 days. Group 3 was treated with Ciprofloxacin $(20 \mathrm{mg} / \mathrm{Kg}$, orally) twice a day for 14 days from day three. Group 4 was administrated with Solanum torvum root extract $(300 \mathrm{mg} / \mathrm{Kg})$ twice a day for 14 days starting from day three. Subjects were treated for a duration of 14 days on third day and seventh day one subject from each group was randomly selected and sacrificed to collect lung tissue for the bacteriological, hematological and histopathological evaluation.

\section{Gross pathological and histological analysis of lungs}

The qualitative analysis of macroscopic lung pathology was examined by considering parameters such as consolidation, abscess, atelectasis and hemorrhage. The lung index of macroscopic pathology (LIMP) was determined by dividing the area of lung showing visible changes by the total area of the same lung [19]. According to the severity of inflammation different scores were allotted such as (i) normal lung, (ii) swollen lungs, hyperemia and small atelectasis, (iii) pleural adhesions and atelectasis and (iv) abscesses, large atelectasis, and hemorrhages [20]. The scoring was performed in a blinded fashion to avoid bias. Microscopic Lung pathology was analyzed by the method described by [21]. Briefly, the tissue samples were collected and preserved in $10 \%$ neutral buffered formalin. The fixed tissues were processed, sectioned and stained with Heamatoxylin \& eosin stain and observed under an upright light microscope. Lung pathology was determined by scoring with respect to severity such as normal histology, mild focal inflammation, moderate to severe focal inflammation with areas of normal tissue; and severe inflammation to necrosis.

\section{Hematological and bacteriological assessment}

Blood was collected upon sacrifice, differential blood count included neutrophils, lymphocytes, monocytes, eosinophils, and basophils. In an aseptic condition, the weighed quantity of lung tissues from each animal was 
collected and homogenized completely under ice cold conditions. The resulting homogenate was then inoculated to Pseudomonas isolation agar plates and incubated for $24 \mathrm{~h}$ at $37^{\circ} \mathrm{C}$. The colonies were counted by digital colony counter. The result was expressed in $\mathrm{CFU} / \mathrm{ml}$ tissue [22].

\section{Statistical analysis}

The data obtained from the study was subjected to statistical analysis. The data was subjected to one-way ANOVA (Analysis of Variance) followed by Dunnett's post test using Graph-pad prism Version 5.01 software.

\section{Results}

\section{Effect of STRE upon in vitro attenuation and growth}

Hostile action of STRE upon quorum sensing controlled virulent properties such as chromogenesis and biofilm formation was found to be prominent against Pseudomonas aeruginosa strain jb07. Bacterial cell adherence was reduced by $91 \%$ when treated with $3 \mathrm{mg} / \mathrm{ml}$ concentration of extract. It was evident that chromogenic property of strain was down regulated as pigment production was reduced to $11 \%$. Quorum quenching ability of extract was directly proportional that with concentration, however there was no any significant difference in bacterial biomass between extract treatment and untreated control which points out that bacterial growth is unaffected by STRE (Fig. 1).

\section{Effect of STRE upon infected rat models}

The observations upon lung infected rat model clearly indicated that treatment with Solanum torvum root extracts could persist the survival of rats challenged with Pseudomonas aeruginosa compared that with untreated positive control. Death of two rats (33.33\%) in untreated group was recorded on 8th day of bacterial inoculation, however none of the untreated subject survived till the end of study period as remaining subjects found dead on 12th day of challenge. There was no mortality reported in negative control, Extract treated group and Ciprofloxacin treated group which suggests the role of STRE upon catalyzing bacterial clearance. Interestingly any kind of significant weight gain or lose was not observed in treatment groups when compared with negative control, though there was an reduction of body weight in untreated group.

\section{Efficacy of treatment upon bacterial clearance}

All the groups other than negative control was infected with sub-lethal dose $\left(1 \times 10^{7} \mathrm{CFU}\right)$ of Pseudomonas aeruginosa challenge strain. The state of bacterial persistence/clearance was analyzed on day 3, day 7 and day 14 (Fig. 2). Bacteriology analysis of lungs on day 3 pointed out that there is no significant difference in the lung bacterial count of untreated group and treated groups which suggested the successful bacterial infection upon study models. On the 7th day of infection a sharp declination up to $81 \%$ lung bacterial count was detected in group 3 which was treated with Ciprofloxacin when compared with untreated positive control. STRE treatment reduced bacterial count to $41 \%$ however it was not so prominent compared with Ciprofloxacin treated group. Lung bacterial count was evaluated on 14th day on group 1,3, 4 whereas bacterial enumeration of group 2 was done on day 12. Higher lung bacterial count of $5.83 \times 10^{7} \mathrm{CFU}$ was observed in positive control though it was interesting to see that final bacterial count in Ciprofloxacin treated group and STRE treated group had insignificant differences as there was complete bacterial clearance occurred. The observation clearly suggests that

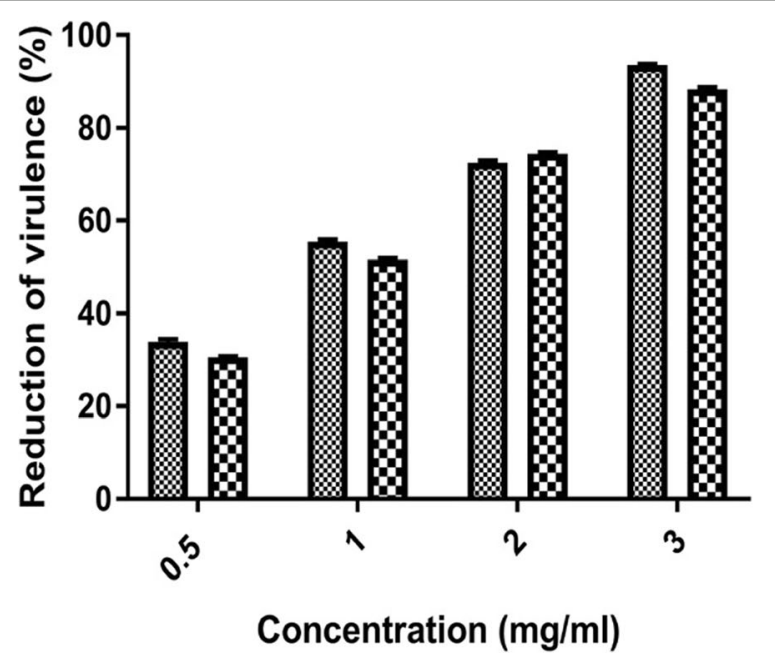

m.m Pigment production

B. Biofilm formation

Fig. 1 Effect of STRE upon quorum sensing dependent functions pigment production and biofilm formation 


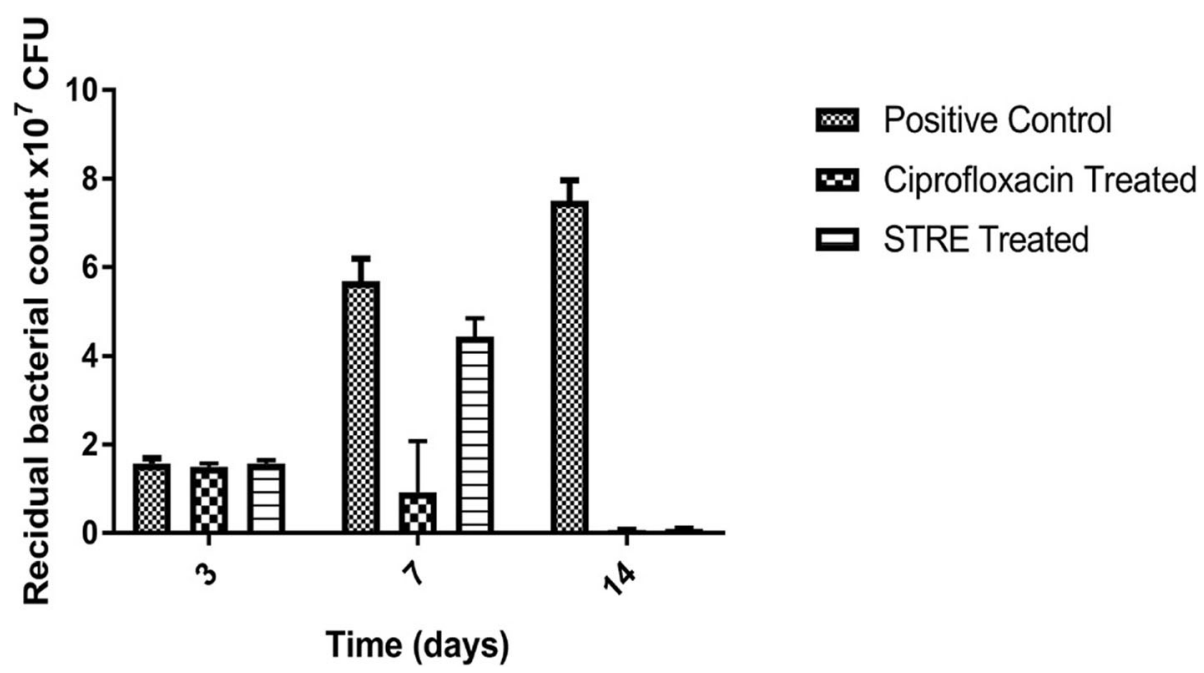

Fig. 2 Efficacy of treatment upon bacterial clearance

extract treatment could immensely influence colonization and persistence by inhibiting bacterial quorum sensing and thereby enhance bacterial clearance.

\section{Gross pathology of lungs}

Macroscopic evaluation and gross pathology of lungs enlightened the physiological and histological changes occurred during the treatment. Sample was analyzed on day 3, 7 and 14 from group 1, 3, 4 whereas specimen from positive control was analyzed on day 3, 7 and 12 . On third day all the groups other than negative control possessed similar kind of clinical signs with slight tumescent lungs due to infection. Interestingly there was notable changes in lung texture among the groups on subsequent analysis. High degree of hemorrhage and abscess was prominent in untreated group on day 7 which supports the death of two subjects of this group on subsequent day. The analysis of STRE treated group possessed inflamed lungs with hyperemia and moderate atelectasis whereas Ciprofloxacin treated group had negligible inflammation however, negative control did not show any abnormal clinical signs. Analysis of lung pathology of dead animals of positive control group on day 12 revealed predominant lung abscesses and hemorrhage due to infection. On 14th day of infection the differences between negative control, STRE treated group and Ciprofloxacin treated group was insignificant in terms of inflammation, lung atelectasis and abscesses moreover there was a significant reduction in clinical signs in group 4 on day 14 compared that with day 7 .

\section{Histopathological investigation of lungs}

Histopathological analysis of lungs was done to evaluate the tissue level changes and physiological alterations due to infection and treatment. Specimen was collected from groups 1, 3, 4 on 3rd, 7th and 14th day of infection whereas sample was taken from untreated group on day 3,7 and 12 due to mortality of subjects. Histopathological observations made upon negative control, positive control, Ciprofloxacin treated group and STRE treated group are given in Figs. 3, 4, 5, 6 respectively. During all three occasions specimen collected from negative control possessed unaltered histology and intact physiology whereas no inflammation was seen. On 3rd day positive control group possessed interstitium thickening and mononuclear cell infiltration however similar response was observed in STRE treated group and Ciprofloxacin treated group. There was notable variation among the groups lately on day 7 , high degree of emphysema and bronchiolar epithelial hyperplasia was observed in untreated group. STRE treated group possessed inflammation, mononuclear cell (MNC) infiltration, polymorpho nuclear (PMN) cells and BALT (bronchus associated lymphoid tissue) hyperplasia. However Ciprofloxacin treated group possessed slight infiltration of mononuclear cells and light inflammation. On day 14 inflammation was found reduced in STRE treated group that compared with day 7 however presence of MNC and PMN cells were detected there were no any traces of emphysema, epithelial hyperplasia or tissue hemorrhage. Tissue histology indicated successful bacterial neutralization by Solanum torvum root extracts. Examination of Ciprofloxacin treated group on day 14 revealed normal lung histology with reversed interstitium thickening and inflammation. Whereas analysis of dead subjects of untreated group revealed total obliteration of lung histology due to large amount of emphysema, epithelial hyperplasia and perivascular fibrosis leading to bronchopneumonia. 


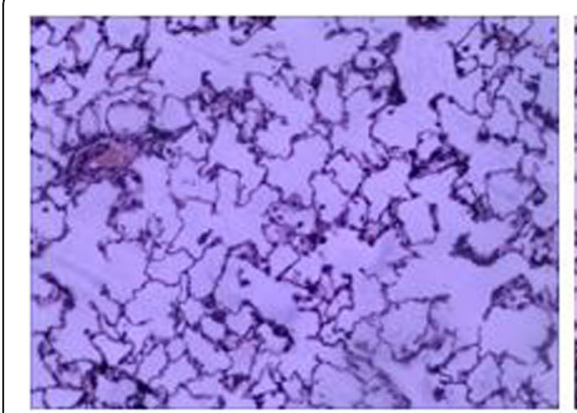

Day 3

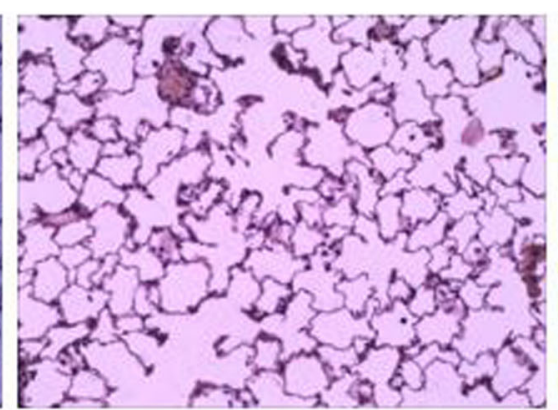

Day 7

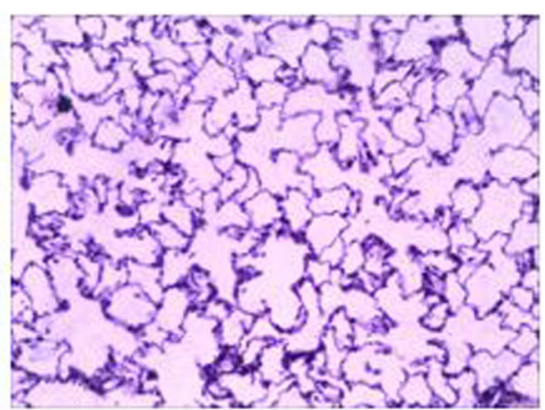

Day 14

Fig. 3 Lung histopathological observation of negative control

\section{Hematological analysis of study animals}

Observations obtained in hematological examination was in correlation with histopathological interpretations. Negative control didn't show any kind of abnormality in differential blood count during entire period of study though there were variations in rest of the groups due to infection. Investigation on day 3 exhibited similar trend of increase in neutrophils, lymphocytes, monocytes eosinophil and basophil counts indicating an immune response in positive control, STRE treated group and Ciprofloxacin treated group, however analysis on day 7 suggested that there is high disparity among these groups. A steep elevation of blood count was recorded in untreated group and STRE treated group whereas only slight increase was there in Ciprofloxacin treated group compared that with rest. Results of day 14 hematological analysis showed decrease of white blood cell count in STRE treated sample compared with day 7 observation. There were no any significant reduction of increase of hematological factors in Ciprofloxacin treated group since day 7. However levels of white blood cells was very high and out of range in untreated group (Table 1).

\section{Discussion}

The number and frequency of mortality due to Pseudomonas aeruginosa infection have increased to a greater extend in recent days, this scenario is immensely favored due to antibiotic resistance. Pseudomonas infections are mostly recurrent which shows inability of immune system to completely irradiate the possibility of successive infection. [23] points out that most of the recurrent $P$. aeruginosa infections in chronic lung disease occurred due to the relapse of prior infections which clearly suggest the inability of current anti-Pseudomonas strategies in absolute bacterial clearance. In this juncture it's more important to concentrate to enhance immune system against such infections rather neutralizing the infections in each occasions which can be achieved by quorum quenching mediated in vivo attenuation and successive bacterial clearance. Bacterial attenuation can be attained by manipulating bacterial quorum sensing network by inhibition of AHL-Lux-R- and Lux-I-type interactions, degradation of existing AHLs, inhibition of enzymes involved in the metabolic synthesis of QS molecules,

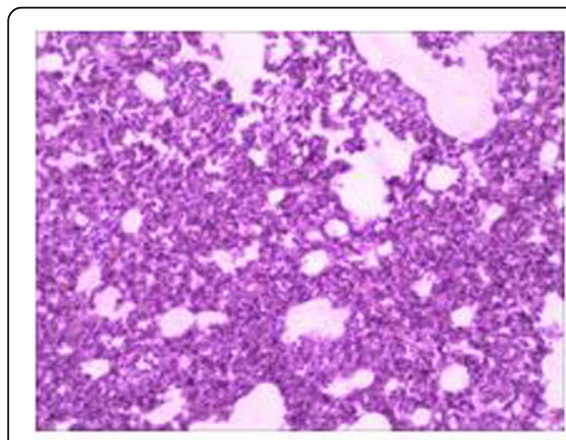

Day 3

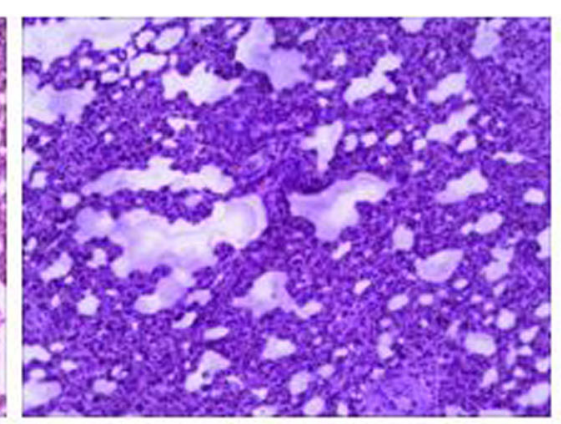

Day 7

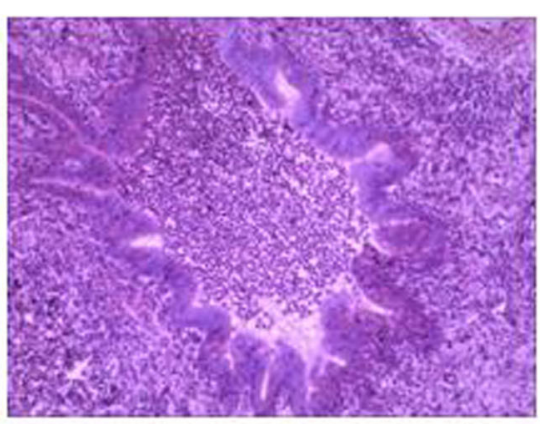

Day 12

Fig. 4 Lung histopathological observation of positive control 


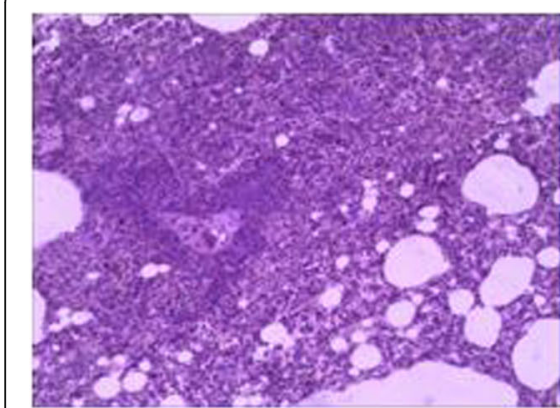

Day 3

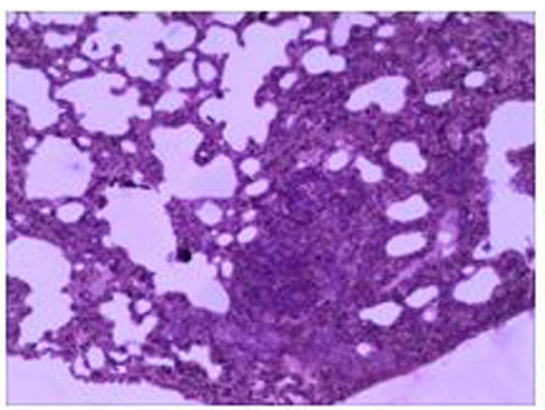

Day 7

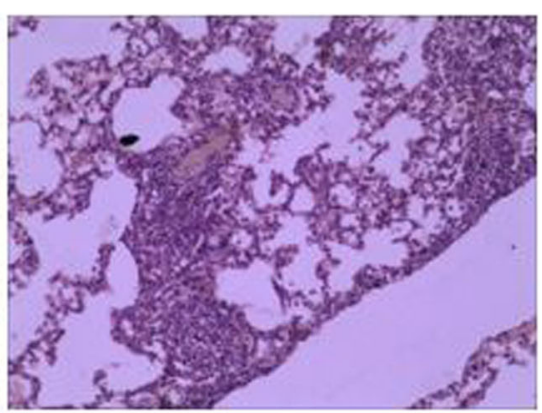

Day 14

Fig. 5 Lung histopathological observation of Ciprofloxacin treated group

blockage of AHL-Lux-R-type binding sites, inhibition of transporters [24].

The effect of Solanum torvum root extracts upon bacterial virulence was analyzed by taking an account of pigment production and biofilm formation which is controlled by quorum sensing. It is been previously reported that the quorum sensing inhibition of Solanum torvum is highly influenced by factors such as bacterial density, concentration of STRE and frequency of administration [25]. Pseudomonas pigment pyoverdin enhance the iron gathering capability of pathogen during infection competing with iron-binding protein transferrin [26]. Iron is as vital factor for microbial virulence, therefore inhibition of pyoverdin leads to iron deficiency in pathogen which in turn inhibit bacterial virulence. It is evident that Pseudomonas aeruginosa respiratory infections initiated by the adherence of the pathogen to the oralpharyngeal mucosa, followed by colonization therefore inability of a pathogen will disable the persistence of infection [27]. Administration of STRE decreased the production of pyoverdin in the test strain along with biofilm formation therefore it is evident that former have immense capability upon attenuating Pseudomonas aeruginosa. Importantly bacterial biomass was not effected by quorum sensing antagonist which suggests that reduction in virulence factors was not because of bacterial death but as a result of bacterial signaling disruption. A similar kind of observation was reported by [28] wherein attenuation of Pseudomonas aeruginosa by quorum sensing inhibitor furanone C-30 isolated from marine algae Delisea pulchra was investigated.

Survival of bacterial infected rats treated by STRE confirms the ability of quorum sensing antagonist to inhibit persistent annexation of pathogens in host. Death of untreated group seen in our studies matching with previous suggestions made by [29] about Pseudomonas infection in lungs cause irreversible lung damage leading to death of host if it is not treated. A significant weight loss is considered to be among the primary symptoms of untreated bacterial sepsis [30] whereas there was no there were no notable weight loss in the STRE treated group, however there was a substantial loss of weight was observed in positive control. This suggest that extract treatment is suppressing all kind of clinical complications due to infection. Fascinatingly similar observations was seen in Ciprofloxacin treated group though the antibacterial

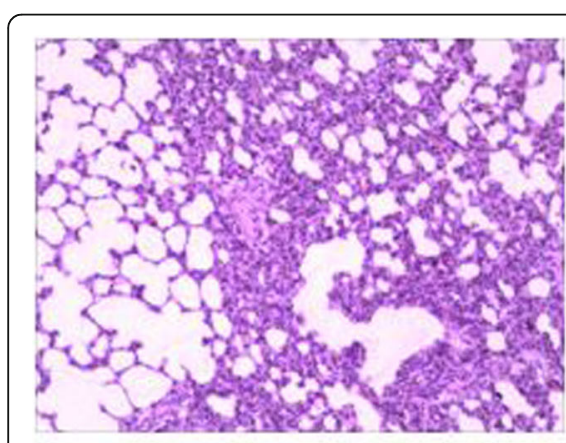

Day 3

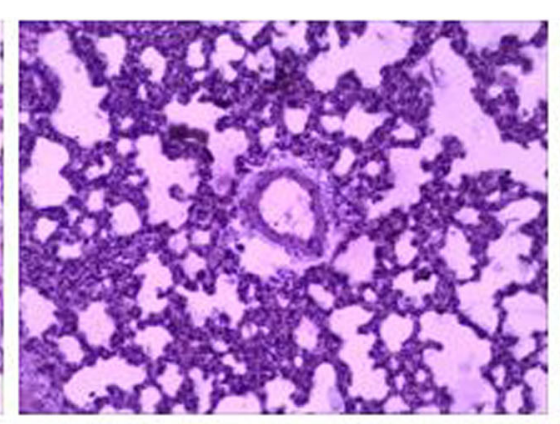

Day 7

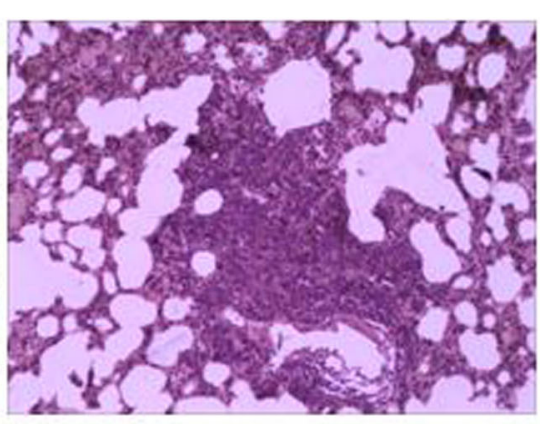

Day 14

Fig. 6 Lung histopathological observation of STRE treated group 
Table 1 Haematological analysis of study animals

\begin{tabular}{|c|c|c|c|c|c|c|}
\hline Groups & Time of analysis & $\begin{array}{l}\text { Neutrophils } \\
\text { [Reference range: } \\
\left.2.00-7.00\left(10^{9} / \mathrm{L}\right)\right]\end{array}$ & $\begin{array}{l}\text { Lymphocytes } \\
\text { [Reference range: } \\
\left.1.00-3.00\left(10^{9} / L\right)\right]\end{array}$ & $\begin{array}{l}\text { Monocytes } \\
\text { [Reference range: } \\
\left.0.20-1.00\left(10^{9} / \mathrm{L}\right)\right]\end{array}$ & $\begin{array}{l}\text { Eosinophils } \\
\text { [Reference range: } \\
\left.0.02-0.50\left(10^{9} / \mathrm{L}\right)\right]\end{array}$ & $\begin{array}{l}\text { Basophils } \\
\text { [Reference range: } \\
\left.0.02-0.10\left(10^{9} / L\right)\right]\end{array}$ \\
\hline \multirow[t]{3}{*}{ Negative Control } & Day 3 & $3.17+/-0.15$ & $1.63+/-0.08$ & $0.44+/-0.05$ & $0.07+/-0.002$ & $0.047+/-0.004$ \\
\hline & Day 7 & $3.262+/-0.14$ & $1.91+/-0.10$ & $0.48+/-0.02$ & $0.08+/-0.007$ & $0.05+/-0.006$ \\
\hline & Day 14 & $3.43+/-0.074$ & $1.47+/-0.09$ & $0.46+/-0.05$ & $0.35+/-0.27$ & $0.042+/-0.002$ \\
\hline \multirow[t]{3}{*}{ Positive Control } & Day 3 & $4.64+/-0.11$ & $2.10+/-0.45$ & $0.87+/-0.18$ & $0.27+/-0.06$ & $0.063+/-0.013$ \\
\hline & Day 7 & $7.42+/-1.66$ & $4.04+/-0.89$ & $1.19+/-0.27$ & $0.42+/-0.10$ & $0.107+/-0.023$ \\
\hline & Day 14 & $9.59+/-2.24$ & $5.42+/-1.31$ & $2.02+/-0.49$ & $0.74+/-0.17$ & $0.17+/-0.04$ \\
\hline \multirow[t]{3}{*}{ Ciprofloxacin treated group } & Day 3 & $4.322+/-0.17$ & $2.02+/-0.06$ & $0.78+/-0.01$ & $0.26+/-0.02$ & $0.068+/-0.003$ \\
\hline & Day 7 & $4.45+/-0.20$ & $2.74+/-0.03$ & $0.65+/-0.02$ & $0.12+/-0.03$ & $0.052+/-0.003$ \\
\hline & Day 14 & $3.44+/-0.23$ & $1.21+/-0.09$ & $0.38+/-0.01$ & $0.05+/-0.001$ & $0.027+/-0.002$ \\
\hline \multirow[t]{3}{*}{ STRE treated group } & Day 3 & $4.76+/-0.08$ & $2.10+/-0.13$ & $0.87+/-0.03$ & $0.33+/-0.02$ & $0.062+/-0.001$ \\
\hline & Day 7 & $6.51+/-0.12$ & $3.56+/-0.10$ & $1.05+/-0.03$ & $0.43+/-0.009$ & $0.083+/-0.003$ \\
\hline & Day 14 & $4.08+/-0.09$ & $1.79+/-0.10$ & $0.49+/-0.04$ & $0.31+/-0.005$ & $0.069+/-0.08$ \\
\hline
\end{tabular}

mechanism of antibiotic and STRE were diverse. Elevated bacterial concentration found in infected groups supports the mortality rate.

Microscopic and macroscopic analysis of lung sample of study animals enlightened the immunological response. Similar kind of histopathology observed in all infected group on day 3, suggest that infection is been successful and there is immunogenicity induced. Observations on seventh day proposed various kind of immune response in different groups, high degree of emphysema and bronchiolar epithelial hyperplasia seen in untreated group can be noted as initiation of lung damage. Very negligible clinical signs was observed in Ciprofloxacin treated group wherein inflammation, MNC infiltration was moderate this suggest that major portion of bacterial clearance is occurred [31]. However the role of host immune system was next to nil in Ciprofloxacin treated group as antibiotic itself possess direct effect upon infection. Interestingly there was no any such action was seen in STRE treated group but host immune response was prominent with inflammation, mononuclear cell (MNC) infiltration, polymorpho nuclear (PMN) cells and BALT (bronchus associated lymphoid tissue) hyperplasia. All these are natural immune response that occur in the time of a lung bacterial infection [32] which states that STRE is not crossing over natural host immune response. At the end of treatment STRE treated group didn't show any clinical signs which indicate whole bacterial clearance like that as Ciprofloxacin treated group, though death of untreated subjects occurred due to infection. This scenario confirms that STRE does not have any direct bactericidal activity like that of Ciprofloxacin but there is successful neutralization of pathogen. It is evident that STRE is giving sufficient time to immune system wherein untreated group subjects are dead before their immune system could do anything.

Importantly it has to be highlighted that STRE does not possess any kind of effect upon bacterial growth and biomass but the histological and hematological investigations points out that immune response found in STRE treated group was natural such as inflammation, Ig elevation and PMN infiltration [33, 34]. However such in vivo attenuation of bacterial pathogens was previously reported by [35] where in Eugenol in combination with lactic acid bacteria attenuated Listeria monocytogenes virulence in invertebrate model Galleria mellonella. The attenuating activity and thereby immunomodulatory effect of Solanum torvum root extract can be explained due to its high quorum quenching ability. A similar kind of quorum quenching mediated in vivo bacterial attenuation was exhibited by Paenibacillus culture extract against Pseudomonas aeruginosa [36].

\section{Conclusion}

Solanum torvum root extract successfully aid the clearance of Pseudomonas aeruginosa infection in infected Sprague Dawley rats. Natural immunological response was exhibited by subjects that treated with STRE which suggests that it is involved in only bacterial attenuation but not interfering immunological response.

\section{Acknowledgements}

We would like to acknowledge Thiruvalluvar Universities for the infrastructure provides.

\section{Authors' contributions}

The idea was conceived and initiated by KV and the methodology and research was carried out by $\mathrm{KV}, \mathrm{JH}$ and VS. All authors read and approved the final manuscript. 


\section{Funding}

This research did not receive any specific grant from funding agencies in the public, commercial, or Not-for-profit sectors.

\section{Availability of data and materials}

The supplementary data will be made available on request.

\section{Ethics approval and consent to participate}

Not applicable

\section{Consent for publication}

All authors unanimously selected the journal for publishing the article.

\section{Competing interests}

The authors declare that they have no competing interests.

\section{Author details}

'Bioresource Technology lab, Department of Biotechnology, Thiruvalluvar University, Vellore, TN 632115, India. ${ }^{2}$ Department of Microbiology, DKM College for women, Vellore, TN 632001, India.

\section{Received: 23 November 2018 Accepted: 17 July 2019}

\section{Published online: 24 July 2019}

\section{References}

1. Waters CM, Bassler BL. Quorum Sensing : communication in Bacteria. Annu Rev Cell Dev Biol. 2005;21:319-46.

2. Rutherford ST, Bassler BL. Bacterial quorum sensing: its role in virulence and possibilities for its control. Cold Spring Harb Perspect Med. 2012;2.

3. Papenfort K, Bassler B. Quorum-sensing signal-response Systems in GramNegative Bacteria. Nat Rev Microbiol. 2016;14:576-88

4. Vadakkan K, Choudhury AA, Gunasekaran R, Hemapriya J, Vijayanand S. Quorum sensing intervened bacterial signaling: pursuit of its cognizance and repression. J Genet Eng Biotechnol. 2018.

5. $\quad \mathrm{Ng} \mathrm{W-L,} \mathrm{Bassler} \mathrm{BL.} \mathrm{Bacterial} \mathrm{quorum-sensing} \mathrm{network} \mathrm{architectures.} \mathrm{Annu}$ Rev Genet. 2009:197-222

6. Van Houdt R, Givskov M, Michiels CW. Quorum sensing in Serratia. FEMS Microbiol Rev. 2007;31:407-24.

7. Smith RS, Iglewski BH. Pseudomonas aeruginosa quorum sensing as a potential antimicrobial target. J Clin Invest. 2003;112:1460-5.

8. Chen F, Gao Y, Chen X, Yu Z, Li X. Quorum quenching enzymes and their application in degrading signal molecules to block quorum sensingdependent infection. Int J Mol Sci. 2013;14:17477-500.

9. Torres M, Uroz S, Salto R, Fauchery L, Quesada E, Llamas I. HaiA, a nove quorum-quenching enzyme which expands the AHL lactonase family. Sci Rep. 2017:7:943.

10. Basavaraju M, Sisnity VS, Palaparthy R, Addanki PK. Quorum quenching: signal jamming in dental plaque biofilms. J Dent Sci Elsevier Taiwan LLC. 2016;11:349-52.

11. Kohanski MA, Dwyer DJ, Collins JJ. How antibiotics kill bacteria: from targets to networks. Nat Rev Microbiol Nature Publishing Group. 2010;8:423-35.

12. Hong KW, Koh CL, Sam CK, Yin WF, Chan KG. Quorum quenching revisitedfrom signal decays to signalling confusion. Sensors. 2012:4661-96.

13. Davies J, Davies D. Origins and evolution of antibiotic resistance. Microbiol Mol Biol Rev. 2010;74:417-33.

14. Akinyemi KO, Oladapo O, Okwara CE, Ibe CC, Fasure KA. Screening of crude extracts of six medicinal plants used in south-west Nigerian unorthodox medicine for anti-methicillin resistant Staphylococcus aureus activity. BMC Complement Altern Med. 2005:5:6.

15. Bonchi C, Frangipani E, Imperi F. Pyoverdine and proteases affect the response of Pseudomonas aeruginosa to gallium in human serum. Antimicrob Agents Chemother. 2015;59:5641-6.

16. Djordjevic D, Wiedmann M, Mclandsborough LA. Microtiter Plate Assay for Assessment of Listeria monocytogenes Biofilm Formation. Appl Environ Microbiol. 2002;68:2950-8.

17. Yan P, Chen Y, Song Z, Wu H, Kong J, Qin X. Pathogenic effects of biofilm with chronic pseudomonas aeruginosa lung infection in rats. J Nanjing Med Univ. 2008:22:34-8.

18. Hoffmann N, Rasmussen TB, Jensen P $\varnothing$, Stub C, Hentzer M, Molin S, et al. Novel mouse model of chronic Pseudomonas aeruginosa lung infection mimicking cystic fibrosis. Infect Immun. 2005;73:2504-14.
19. Song Z, Wu H, Mygind P, Raventos D, Sonksen C, Kristensen H, et al. Effects of Intratracheal administration of Novispirin G10 on a rat model of mucoid Pseudomonas aeruginosa lung infection. Antimicrob Agents Chemother. 2005:49:3868-74.

20. Johansen HK, Espersen F, Cryz SJ, Hougen HP, Fomsgaard A, Rygaard J, et al. Immunization with Pseudomonas aeruginosa vaccines and adjuvant can modulate the type of inflammatory response subsequent to infection. INFECrION Immun. 1994;62:3146-55.

21. Song Z, Kharazmi A, Wu H, Faber V, Moser $C$, Johansen HK, et al. Effects of ginseng treatment on neutrophil Chemiluminescence and immunoglobulin $G$ subclasses in a rat model of chronic Pseudomonas aeruginosa pneumonia. Clin Diagn Lab Immunol. 1998;5:882-7.

22. Akkaya B, Turkay C, Saba R, Pahin N, Altunbap H, Turkay M, et al. Effect of chronic Pseudomonas aeruginosa infection on the development of atherosclerosis in a rat model. Clin Microbiol Infect. 2004:5-8.

23. Yum H, Park I, Shin B, Choi S. Infection in chronic lung Diseases : relapse or Reinfection ? Tuberc Respir Dis. 2014:3536:172-7.

24. Singh RP. Attenuation of quorum sensing-mediated virulence in gramnegative pathogenic bacteria: implications for the post-antibiotic era. Med Chem Commun. 2015:259-72.

25. Vadakkan K, Vijayanand S, Choudhury AA, Gunasekaran R, Hemapriya J. Optimization of quorum quenching mediated bacterial attenuation of Solanum torvum root extract by response surface modelling through boxBehnken approach. J Genet Eng Biotechnol. 2018.

26. Meyer J, Neely A, Stintzi A, Georges C, De ML, Ge D. Pyoverdin is essential for virulence of Pseudomonas aeruginosa. Infect Immun. 1996:64:518-23.

27. Franklin AL, Todd TOM, Gurman G, Black D, Mankinen-irvin PM, Irvin RT. Adherence of Pseudomonas aeruginosa to cilia of human tracheal epithelial cells. Infect IMMUNITY. 1987;55:1523-5.

28. Hentzer M, Wu H, Andersen JB, Riedel K, Rasmussen TB, Bagge N, et al. Attenuation of Pseudomonas aeruginosa virulance by quorum sensing inhibitors. EMBO J. 2003;22:3803-15.

29. Ernst EJ, Hashimoto S, Guglielmo J, Sawa T, Pittet J, Kropp H, et al. Effects of antibiotic therapy on Pseudomonas aeruginosa - induced lung injury in a rat model. Antimicrob Agents Chemother. 1999:43:2389-94.

30. Breuille D, Voisin L, Contrepois M, Arnal M, Rose F, Obled C. A sustained rat model for studying the long-lasting catabolic state of Sepsis. Infect Immun. 1999;67:1079-85.

31. Kemmerich B, Small GJ, Pennington JE. Comparative evaluation of ciprofloxacin, Enoxacin, and Ofloxacin in experimental Pseudomonas aeruginosa pneumonia. Antimicrob Agents Chemother. 1986;29:395-9.

32. Lavoie EG, Wangdi T, Kazmierczak BI. Innate immune responses to Pseudomonas aeruginosa infection. Microbes Infect. 2012;13:1133-45.

33. Eisele NA, Anderson DM. Host defense and the airway Epithelium : frontline responses that protect against bacterial invasion and pneumonia. J Pathog. 2011;2011.

34. Craig A, Mai J, Cai S, Jeyaseelan S. MINIREVIEW neutrophil recruitment to the lungs during bacterial pneumonia. Infect Immun. 2009;77:568-75.

35. Upadhyay A, Upadhyaya I, Mooyottu S. Eugenol in combination with lactic acid bacteria attenuates listeria monocytogenes virulence in vitro and in invertebrate model galleria mellonella. J Med Microbiol. 2016:443-55.

36. Alasil SM, Omar R, Ismail S, Yusof MY. Inhibition of quorum sensingcontrolled virulence factors and biofilm formation in Pseudomonas aeruginosa by culture extract from novel bacterial species of Paenibacillus using a rat model of chronic lung infection. Int J Bacteriol. 2015:2015.

\section{Publisher's Note}

Springer Nature remains neutral with regard to jurisdictional claims in published maps and institutional affiliations. 